\title{
UNDERSTANDING ENVIRONMENTAL INCIDENTS ON CONSTRUCTION SITES IN AUSTRALIA: THE CAUSAL FACTORS, ENVIRONMENTAL IMPACT AND THEIR RELATIONS
}

\author{
Jelena M. ANDRIĆ ${ }^{1}$, Jiayuan WANG ${ }^{1^{*}}$, Abdul-Majeed MAHAMADU², Ruoyu ZHONG ${ }^{3}$ \\ ${ }^{1}$ College of Civil and Transportation Engineering, Shenzhen University, Shenzhen, P.R. China \\ ${ }^{2}$ Department of Architecture and the Built Environment, University of the West of England, Bristol, UK \\ ${ }^{3}$ China Center for Special Economic Zone Research, Shenzhen University, Shenzhen, P.R. China
}

Received 24 January 2019; accepted 06 May 2019

\begin{abstract}
The construction sites are prone to environmental incidents. In this paper, the root causes of incidents and immediate actions taken after events are identified through qualitative analysis, while the environmental impacts, the cost of mitigation, time of incident occurrence, as well as the relationship between the causes of incidents and immediate actions and the causes and environmental impacts were quantitatively analysed. In total, 499 environment incidents occurred over an 8-year period on the construction sites in Australia was examined in this study. The results show that the most common causes of incidents were equipment and plant failure, oil spillage, and fuel spillage, while the most expensive incidents in terms of mitigation were flooding, poor weather, and process failures. Further, the most common actions taken immediately after incidents were cleaning and clearing, shut down of operation, plant and equipment and notifications. More than $50 \%$ of incidents resulted in the contamination of land and groundwater, while the majority of incidents occurred between 10:00 am and 12:00 am. We propose strategies for project managers and environmental managers to better understand potential environmental hazards.
\end{abstract}

Keywords: environmental incidents, causes, immediate actions, environmental impact, environmental management, construction sites, Australia.

\section{Introduction}

Similar to natural disasters, environmental incidents tend to occur unexpected and could present a major threat to environment and society. Environmental incident is an event that may cause potential damage to an environmental receptor, air, water, land, wildlife or local habitat. According to the Department of Transport and Main Roads (2017) of Queensland Government in Australia, "environmental incident is where actual environmental harm occurs, or there is a situation where there is a real chance that environmental harm could occur; unauthorised damage to cultural, built heritage, artefacts or ship wrecks and unlawful under any environmental or cultural heritage legalisation". Generally, environmental incidents occur suddenly exposing the great risks to environment, production and social life (Wiens \& Parker, 1995). Also, these incidents are considered as outbreak of sudden environment risk event. When environment incident happened, it often has debilitating effects on the external environment and health consequences on humans and animals through release of contaminants or effluents into water, land or atmosphere overall (Cao et al., 2018).

During the construction process, workers are operating in multiple injury-inducing hazard environment and occupational accidents are common on construction sites. Compared to other industries, the rate of occupational accidents in construction industry is the highest (Lehtola et al., 2008). Besides occupational accidents, construction sites are exposed to environmental hazards (Y. A. Kim, Ryoo, Y. S. Kim, \& Huh, 2012) which could lead to environmental incidents.

Construction projects, especially complex infrastructure projects involve bulk earthworks, pipe lying and other process operated by heavy machines and equipment in sensitive ground locations (Guerin, 2002). As a result of heavy machines' operation process, frequently spills of oil, fuel, and coolants could occur and pose a direct or indirect threat to the environment, flora and fauna (Guerin, 2015). Hence, spills of petroleum and hydrocarbons are of great concern on construction sites (Taylor, 2007). Furthermore,

*Corresponding author. E-mail: wangjy@szu.edu.cn 
construction industry is one of the key sources of pollution in the world (Zolfagharian, Nourbakhsh, Irizarry, Ressang, \& Gheisari, 2012). While in the USA, it has been ranked on the first place as the major source pollution for decades (Sharrard, Matthews, \& Roth, 2007). Globally, construction of infrastructure and building projects consume large amounts of energy and resources, and contribute to the high generation of waste and pollution (Ortiz, Castells, \& Sonnemann, 2009).

Due to the lack of studies of the environmental incidents on construction sites (Kim et al., 2012), hence there is a need for more systematic studies on the environmental hazards on construction sites, their root causes, immediate actions and the relations between causes and impacts. The other issue is those lessons learned from incidents are not efficiently transferred to contractors and project managers in order to reduce the frequency of their occurrence and severity in the future (Fraser, Ellis, \& Hussain, 2008). To bridge these gaps, the aims of this paper are: 1) to identify the root causes, immediate actions and impacts of environmental incidents; 2 ) to estimate the costs of mitigation measures for environmental incidents on construction sites; 3 ) to determine relationship between the causes and immediate actions and causes and environmental impacts; and 4) to propose strategies to reduce or prevent incidents. The characteristics of environmental incidents which occur on the construction sites are of significant importance to the project and environmental manager. In this paper, a framework for environmental incident analysis is developed and used to identify the causes of environmental incidents, immediate actions, and environmental impacts, estimate the cost of mitigation, and determine the relationships between the causes of environmental incidents and immediate actions and the causes and environmental impacts. The proposed methodology for environmental incident analyses combines qualitative approach with different quantitative methods. To identify the causes of environmental incidents and immediate actions, qualitative analysis, and root cause analysis are conducted. The cost of mitigation is estimated through the statistical approach, while descriptive statistics are used to determine the relations between the causal factors and immediate actions and the causal factors and environmental impacts.

\section{Literature review}

Environmental incidents have tendency to occur suddenly and cause major influence to the environment and society, hence there are a significant number of studies related to this phenomena in different industries and countries. Also, different statistical methods are used in analyses of environmental incidents in the current literature (Shin, 2013). However, the focus of this study is on the environmental incidents on construction sites.

Regarding environmental hazards in the construction industry, Chen, Li, and Wong (2000) proposed a systematic approach to environmental management of pollution and hazards caused by urban construction projects in China.
This systematic approach combines qualitative analysis to identify, assess and control risks and a quantitative method to estimate construction pollution index. Further, Chen, $\mathrm{Li}$, and Wong (2005) have investigated the environmental impacts of construction process and categorised them into: soil and ground contamination, construction and demolition waste, surface and underground water contamination, dust, noise and vibration, impacts on wildlife and natural features, hazardous emissions and archaeological impacts. According to the Environment Protection Department of Hong Kong Government, the environmental impacts of construction activities on sites in Hong Kong are air pollution, water pollution, waste pollution and noise pollution (Shen \& Tam, 2002). Further, the environmental impacts of construction sites have been focus of study by Sharrard et al. (2007) and it is concluded that construction activities have a significant impact in storm water management, demolition debris and energy consumption. The energy consumption on the construction sites is responsible for air emissions since some of the energy is provided through diesel fuel and electricity. The majority of this energy is used by large construction vehicles and equipment. Gangolells et al. (2009) have investigated the environmental impacts of construction processes in case of the residential buildings. The identified environmental impacts of construction processes were emissions to air; release to water; avoidance, recycling, reuse, transportation and disposal of solid and other wastes; use and contamination of land; use of natural resources and raw materials (including energy); local issues (noise, vibration, dust, visual appearance, etc.); transport issues; risk of environmental accidents and impacts arising as consequences of incidents, accidents and potential emergency situations; and effects on biodiversity.

In studies related to mitigation of environmental risks, Dione, Ruwanpura, and Hettiaratchi (2005) developed a framework for environmental risk identification and applied on construction sites in Canada. As suggested mitigation measures for these environmental hazards, environmental-type insurance and contractual liability indemnity clauses are recommended. Guerin (2014) performed an analysis of 373 plant spills from construction sites of liquid natural gas plant projects in Western Australia through the client's "5-why" investigation process and root cause analysis. The focus of his study was on the root causes of hydrocarbon spills on construction sites. The results showed that the root causes of these spills were: failure in procedure and safe work practice, risk management, failure in preventive maintenance/repeat failures, design, inspection and quality control, training, and competency, misunderstood in communication, lack of communication and turnover needs improvement.

To sum up, the current literature on environmental incidents of construction activities reveals that there are a major studies related to the environmental impact, but there is a lack of studies related to the identification of casual factors of environmental incidents and root causes (Fuertes et al., 2013), as well as relationships between the causality and environmental impacts (Perdicoúlis \& Piper, 2008). 


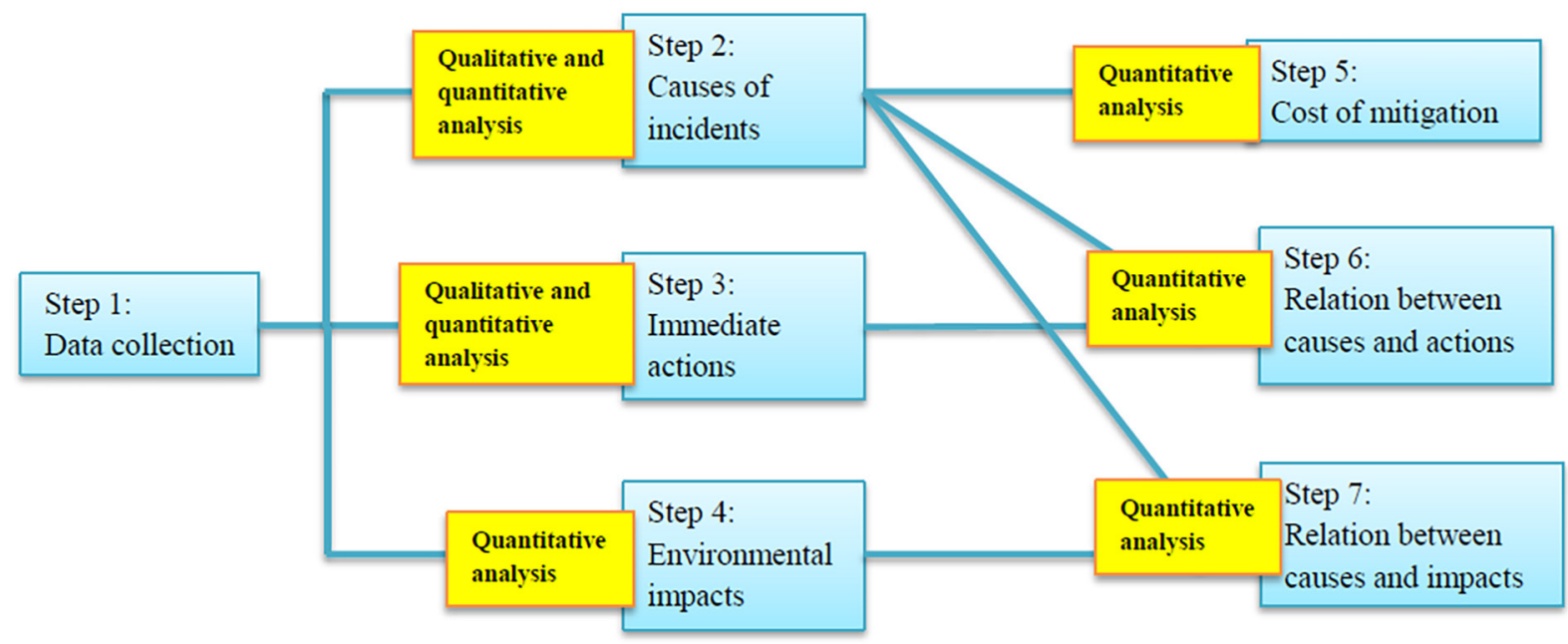

Figure 1. The framework for environmental incident analysis

\section{Research methodology}

\subsection{Framework for environmental incident analysis}

The proposed framework describes the process of environmental incident analysis and management as depicted in Figure 1. Firstly, the data were collected from reports of environmental incidents across construction sites in Australia. From this data, the causes of environmental incidents and immediate actions were identified through qualitative analysis and evaluated through quantitative analysis. Subsequently, the environmental impact of each incident was quantitatively analyzed to provide details about the most common impacts of an environmental incident. The mean value and standard deviation of mitigation cost were estimated through probabilistic and statistical approach. In addition, the quantitative analysis was used to establish the relationship between the causes of incidents and immediate actions and causes of environmental incidents and environmental impact. As a result of the study, mitigation measures for environmental incidents were proposed which can be applied to other sites, not limited to Australian construction sites.

\subsection{Data collection}

The data is gathered from more than 200 construction projects across Australia provided by three leading Australian Contractors. The content of environmental incident report contains information about project name, location, date and time of occurrence, project type, description of event, immediate action taken, environmental impact, the outcome of the incident, and cost of mitigation. In total, 499 different cases of environmental incidents are considered. These incidents have occurred on different types of construction projects including building projects, railways, pipelines, bridges, marine structures, and other infrastructures during the 8-year period between 2008 and 2016. Table 1 provides information about the number of incidents per states in Australia and year of occurrence. The majority of incidents occurred in Queensland, while New South Wales and Western Australia are ranked on the second and the third place, respectively. On the other hand, the least incidents occurred in Tasmania and Australian Capital Territory. From 2008 to 2012, the number of incidents per year increased steadily and reached a peak in 2012. In the following years, the trend of incidents indicates a dramatic fall of incidents.

Table 1. The number of incidents per state and year

\begin{tabular}{|l|c|c|c|c|c|c|c|c|c|c|}
\hline \multicolumn{1}{|c|}{ StatelYear } & 2008 & 2009 & 2010 & 2011 & 2012 & 2013 & 2014 & 2015 & 2016 & Total \\
\hline Queensland & 5 & 8 & 20 & 14 & 39 & 21 & 17 & 10 & 0 & 134 \\
\hline New South Wales & 1 & 5 & 9 & 16 & 31 & 27 & 17 & 9 & 3 & 119 \\
\hline Western Australia & 1 & 4 & 11 & 23 & 24 & 21 & 10 & 6 & 1 & 101 \\
\hline Victoria & 1 & 5 & 12 & 8 & 8 & 6 & 4 & 11 & 10 & 65 \\
\hline Northern Territory & 0 & 0 & 0 & 0 & 13 & 21 & 4 & 0 & 1 & 39 \\
\hline South Australia & 0 & 0 & 0 & 6 & 12 & 11 & 0 & 4 & 0 & 33 \\
\hline Australian Capital Territory & 0 & 3 & 0 & 1 & 2 & 0 & 0 & 0 & 0 & 6 \\
\hline Tasmania & 0 & 1 & 1 & 0 & 0 & 0 & 0 & 0 & 0 & 2 \\
\hline Total: & 8 & 26 & 53 & 68 & 130 & 107 & 52 & 40 & 15 & 499 \\
\hline
\end{tabular}




\subsection{Methods for environmental incident analysis}

In the previous studies, probabilistic and statistical methods were commonly applied in analyses of environmental incidents (Cao et al., 2018). However, this study combines qualitative and quantitative methods to analyse environmental incidents on construction sites such as content analysis, text mining, root cause analysis, as well as probabilistic and statistical methods. Firstly, the qualitative data analysis of incident reports is carried out in order to identify the causes of incidents and immediate actions. Further, a probabilistic and statistical approach is applied to determine the cost of different causes of incidents, environmental impacts and time of incident occurrence and to establish the relationship between causes and immediate actions and the relationship between causes of incidents and environmental impact. Root Cause Analysis (RCA) is an efficient tool for investigating the key factors of accidents, incidents, and faults (Rooney \& Heuvel, 2004), which is based on systematic reporting of adverse events, their layers to determine the relative priority, investigation and production of recommendations. RCA is a method used to investigate, identify, understand and resolve any root cause of problems and incidents (Carroll, 1998). For implementing RCA in this study, graphs are selected. In general, RCA is composed of five essential steps: 1) define the problem; 2) collect data; 3) identify possible casual factors; 4) identify root causes, and 5) recommend and implement strategies to reduce incidents occurrence. In this study, RCA is applied to identify the causes of incidents.

The most suitable software for qualitative data analysis is Nvivo12 since it enables coding and categorization of data, understanding phenomenon, developing construct and developing theory (Adu, 2015). In qualitative analysis, coding is defined as a linking from the data to the idea and back to other data (Saldaña, 2013). Usually, it represents cycling process. A code is defined as: "a word, phrase or sentence that represents aspects of a data or captures the essence of features of a data" (Saldaña, 2013). The incidents with the similar causes are coded into the same nodes, and node identifies the cause of incidents. Correspondingly, immediate actions are coded into nodes. Some of the NVivo12 analyses are performed in order to identify and obtain the characteristics of the causes of incidents and immediate actions. The selected analyses from $\mathrm{NVi-}$ vo12 are the following: Word cloud analysis, cluster analysis, and tree map analyses. Word cloud analysis is a data exploration technique which is used to analyse the content of the causes of incidents and immediate actions indicated by high-frequency words. This analysis provides information about the keywords from reports which are the most common words in reports. Cluster analysis is an exploratory technique that provides a diagram, in which nodes are grouped according to similar words which they share, similar attributes or similarity in nodes coding. Further, cluster analysis is a graphical representation of nodes to show their similarities and differences. In this research, cluster analysis by word similarity is performed for providing a more detailed relationship between coded nodes. The tree map is a diagram of hierarchical data representation, in which data is described by a set of nested rectangles of different sizes. In order to compare the number of coding references, treemap of nodes is created. A node with the most coding references is displayed as the largest rectangle, while the node with the least coded references is displayed as the smallest rectangle in the tree map diagram. To determine the quantity of each cause of incidents and immediate actions which appears in reports, this analysis can be applied. Also, the results could be validated through quantitative analysis.

To quantitatively analyse the causes of incidents, immediate actions, environmental impacts, and time of environmental incidents, descriptive statistical analysis is applied due to the fact that environmental incidents can be considered as outbreaks of unexpected environmental risk events (Lu, Sun, Xia, \& Hou, 2012). The descriptive analysis defines the probability of occurrence of an environmental incident in each category as ratios between the numbers of incidents occur in particular category and the total number of observed incidents (Yang et al., 2010).

\section{Results}

\subsection{Causes of environmental incidents and cost mitigation}

Overall, 21 causes of environmental incidents are identified through RCA and coding the data in NVivo12. According to RCA, the causes of environmental incidents on construction sites are as follows: equipment and plant failure, oil spillage, fuel spillage, poor weather, process failures and other causes of incidents as listed in Table 2. Usually, equipment and plant failure results in releasing substances or liquids harmful to the environment. Vehicular accidents occurred when car/truck hit kangaroo or trees. Working hours is an incident related to work in the evening after the regular working time or during the night causing disturbance of the local community.

Word cloud analysis (Figure 2) based on words frequency shows that the most frequent incidents in reports were spills, which indicate that the majority of incidents were due to equipment and plant failure which resulted in a spill, oil spills, fuel spills, and other spills. Further, the other frequent words in reports are site, water, hydraulic, oil, and project. The items clustered by word similarity are shown in Figure 3. It can be concluded that there is a similarity between 1) equipment and plant failure and oil spillage; 2) poor weather and water spillage; 3 ) human errors and poor judgment and operative failures; 4) archaeological and heritage incidents and intrusion by wildlife; 5) fire - flammable substance and fire-weather; 6) construction material spillage and process failures; and 7) trespassing by public and working hours. Tree map analysis based on the amount of coding references is illustrated in Figure 4. According to the size of rectangles, 
Table 2. Causes of environmental incidents

\begin{tabular}{|c|c|c|}
\hline \multirow{2}{*}{ Causes of incidents } & \multirow{2}{*}{ Descriptive statistics } & Cost of Mitigation $(A U D)$ \\
\hline & & Mean Value \pm Std. Dev. \\
\hline Equipment and plant failure & $24 \%$ & $537.45 \pm 1229$ \\
\hline Oil spillage & $10 \%$ & $372.89 \pm 587$ \\
\hline Fuel spillage & $8 \%$ & $300.14 \pm 529$ \\
\hline Poor weather & $8 \%$ & $2135.8 \pm 7797$ \\
\hline Process failures & $7 \%$ & $1866.1 \pm 7371$ \\
\hline Human error and poor judgment & $6 \%$ & $465.18 \pm 733$ \\
\hline Operative failure to adhere to procedures & $6 \%$ & $1158.9 \pm 3013$ \\
\hline Poor waste disposal and management & $4 \%$ & $811.12 \pm 1408$ \\
\hline Archaeological and heritage incident & $4 \%$ & $900.32 \pm 2827$ \\
\hline Construction material spillage & $4 \%$ & $302.78 \pm 407$ \\
\hline Effluent spillage & $3 \%$ & $429.45 \pm 744$ \\
\hline Intrusion by wildlife & $3 \%$ & $74.07 \pm 72$ \\
\hline Chemical spillage & $2 \%$ & $270.4 \pm 314$ \\
\hline Trespassing by public & $2 \%$ & $567.68 \pm 1535$ \\
\hline Vehicular accidents & $1 \%$ & $116.67 \pm 136$ \\
\hline Maintenance failures & $1 \%$ & $376.67 \pm 334$ \\
\hline Working hours & $1 \%$ & $23.22 \pm 61$ \\
\hline Water spillage & $1 \%$ & $140.14 \pm 225$ \\
\hline Fire - flammable substances & $1 \%$ & $808.58 \pm 1135$ \\
\hline Flooding & $1 \%$ & $5570 \pm 1227$ \\
\hline Fire - weather (bushfire) & $1 \%$ & $854.28 \pm 1834$ \\
\hline
\end{tabular}

\section{on}

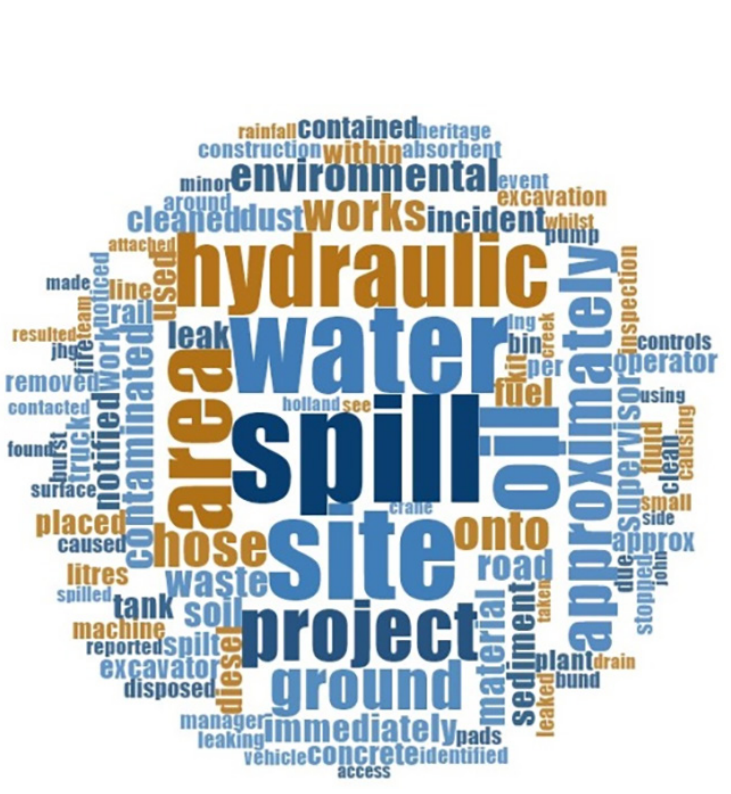

Figure 2. Word cloud analyses of causes of incidents nodes the most common causes of incidents are equipment and plant failure, oil spillage and fuel spillage. The breakdown of equipment and plant on the construction sites could result in different kinds of spillages. In the most cases of the breakdown of equipment, hose burst occurred during construction process which leads to spillages. On the other hand, the least common causes of incidents are flooding and fire - flammable substances. Usually, flooding on the site appears due to heavy rainfall. In addition, the quantitative analysis of the causes of incidents is carried out and results are presented in Table 2 . These results are in the alignment with the previous results obtained from qualitative analysis in Figure 5. Since these results are obtained through quantitative analysis by descriptive statistics, the exact percentage of each cause of incidents are estimated in Table 2. Overall, 24\% of incidents are caused by the equipment and plant failure; $10 \%$ of incidents are the result of oil spillage; and $8 \%$ of incidents are triggered by fuel spillage, while other $8 \%$ of incidents are caused by poor weather. Among the least common incidents are vehicular accidents (1\%), maintenance failure (1\%), working hours $(1 \%)$, water spillage $(1 \%)$, fire - flammable substances 
Items clustered by word similarity

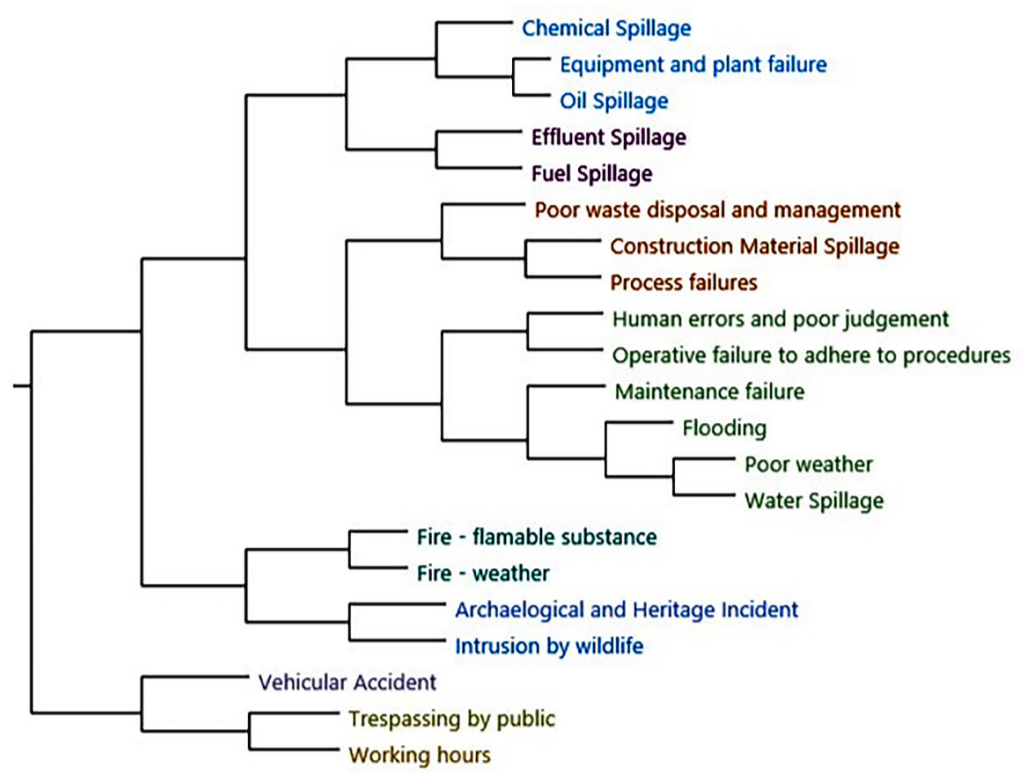

Figure 3. Causes of incidents nodes clustered by word similarity

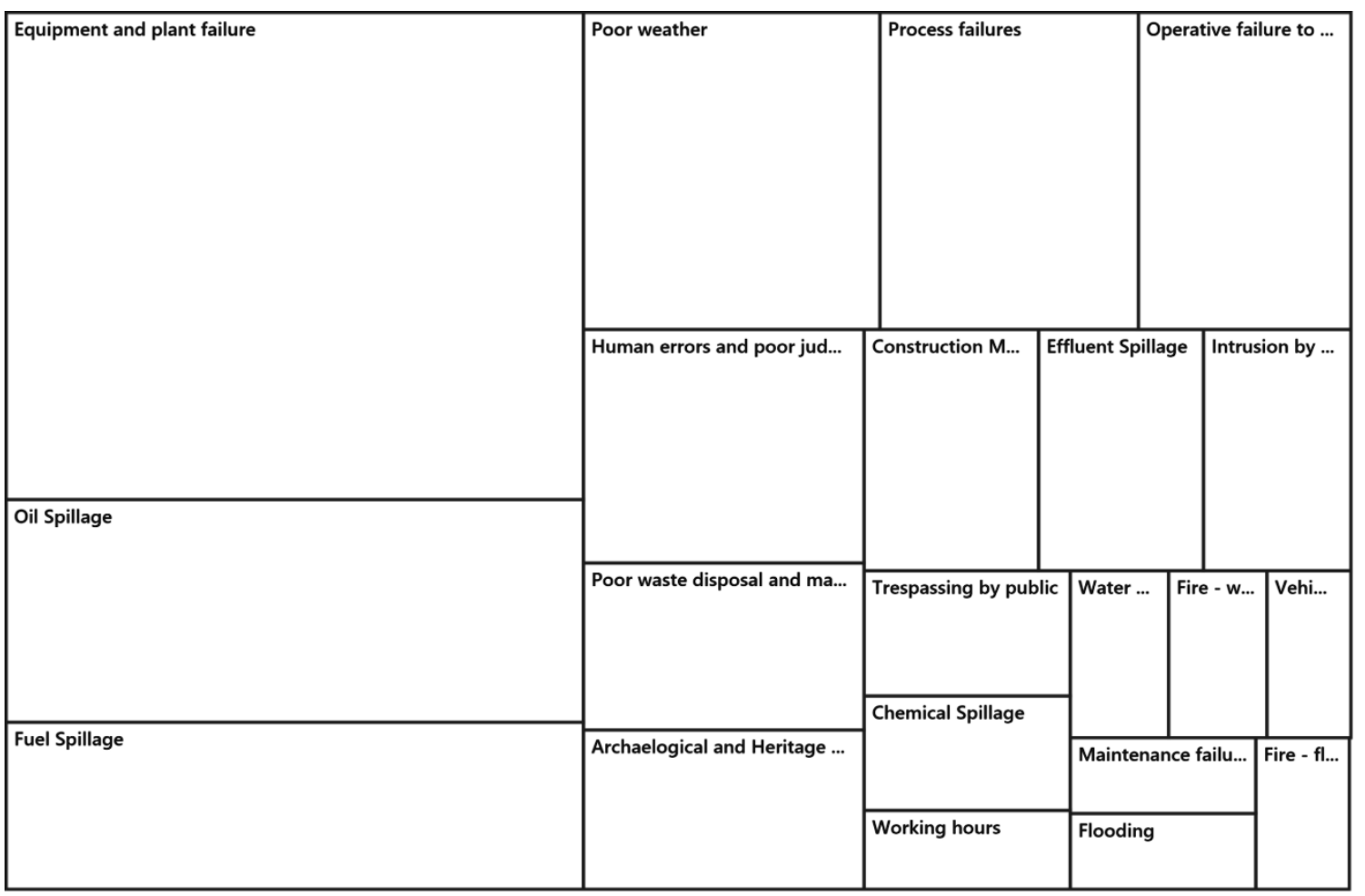

Figure 4. Tree map analysis - compared by number of coding references (nodes)

(1\%), fire - weather (1\%), and flooding (1\%). In addition, the mean value of mitigation cost and a standard deviation is estimated for each cause of incidents and results are provided in Table 1. According to results, the most expensive were incidents caused by flooding on the site with the mean value of AUD 5570.2 (std. dev. of AUD 1227); followed by incidents caused by poor weather with mean value AUD 2135.8 (std. dev. of AUD 7797) and process failures with the mean value of AUD 1866.1 (std. dev. of AUD 7371). The consequences of flooding, poor weather and process failures are higher than the consequences of other incidents. The least expensive incidents were working hours and intrusion by wildlife. Flooding has a very low probability of occurrence (1\%), but it has the highest impact. Hence, flooding can be described as a very lowprobability incident with very high impact. Poor weather 
is among the top four most common incidents and it is ranked in the second place among the most expensive incidents. Thus, poor weather is a high-probability incident with a high impact. Further, equipment and plant failure are very high-probability incident with the medium impact. On average, the cost of equipment and plant failure is in the middle. Similarly, oil spillage is a high-probability incident with the medium impact.

\subsection{Immediate actions for environmental incidents}

When incidents occur, immediate actions are taken to eliminate the consequences. In total, 13 immediate actions are detected through qualitative analysis using coding in NVivo12. The immediate actions and the percentage of each taken actions estimated by quantitative analysis is listed in Table 3. Multiple immediate actions are taken in mostly of cases due to severity of incidents. For example, some incident required cleaning and clearing and notification.

Table 3. Immediate actions

\begin{tabular}{|l|c|}
\hline \multicolumn{1}{|c|}{ Immediate actions } & $\begin{array}{c}\text { Descriptive } \\
\text { statistics }\end{array}$ \\
\hline Cleaning and clearing & $47 \%$ \\
\hline Shut down of operations, equipment and plants & $31 \%$ \\
\hline Notification & $24 \%$ \\
\hline Repair damage & $12 \%$ \\
\hline Investigation & $11 \%$ \\
\hline Reporting & $9 \%$ \\
\hline Building of temporary structures for mitigation & $5 \%$ \\
\hline Removal of substances and contaminants & $5 \%$ \\
\hline Monitor environment & $3 \%$ \\
\hline Wildlife protection and removal & $3 \%$ \\
\hline Archaeological protection and removal & $2 \%$ \\
\hline Extinguish fire & $2 \%$ \\
\hline Vegetation protection and removal & $2 \%$ \\
\hline
\end{tabular}

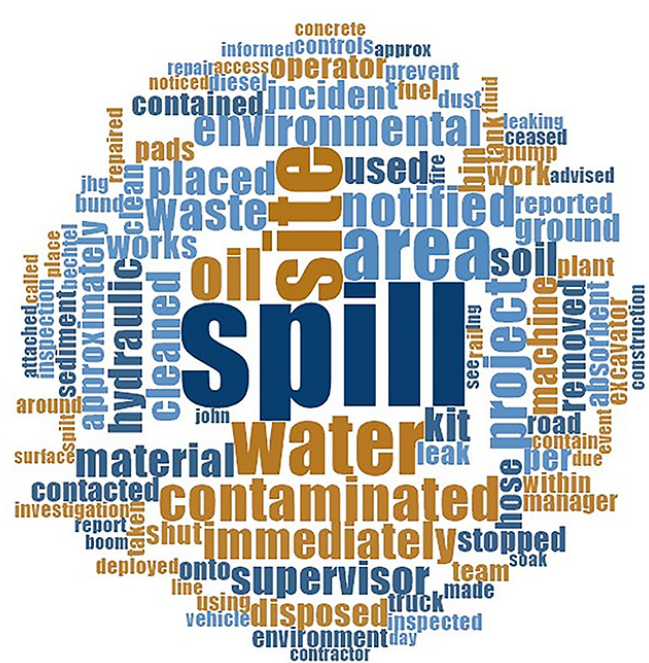

Figure 5. Word cloud analysis for immediate actions

In the case of immediate actions, word cloud analysis (Figure 5) indicates that the most frequent word is a spill, which is similar to results causes of incidents. Also, the other frequent words are similar as in the case of causes of incidents: site, water, oil, and project. However, the additional word is an area. Items clustered by word similarity have shown the similarities between immediate action nodes. According to clustered analysis (Figure 6), there is word similarity between 1) notification and reporting; 2) repair damage and shut down of operations, equipment and plants; and 3) archeological protection and removal and monitoring environment. Further, tree map analysis based on the number of coded references show that cleaning and clearing, shut down of operation, equipment, and plants, and notification is three most common taken actions after incidents occur (Figure 7). According to quantitative analysis in Table 2, $47 \%$ of immediate actions are cleaning and clearing, $31 \%$ is shut down of operations, equipment and plants and $24 \%$ is notification. On the other hand, the least taken immediate actions are: monitor environment (3\%), wildlife protection and removal (3\%),

Items clustered by word similarity

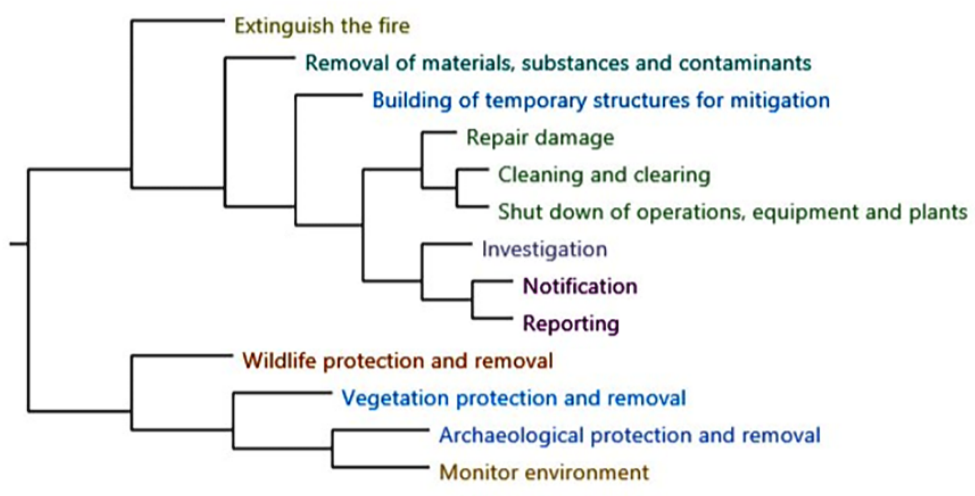

Figure 6 . Immediate actions nodes clustered by word similarity 


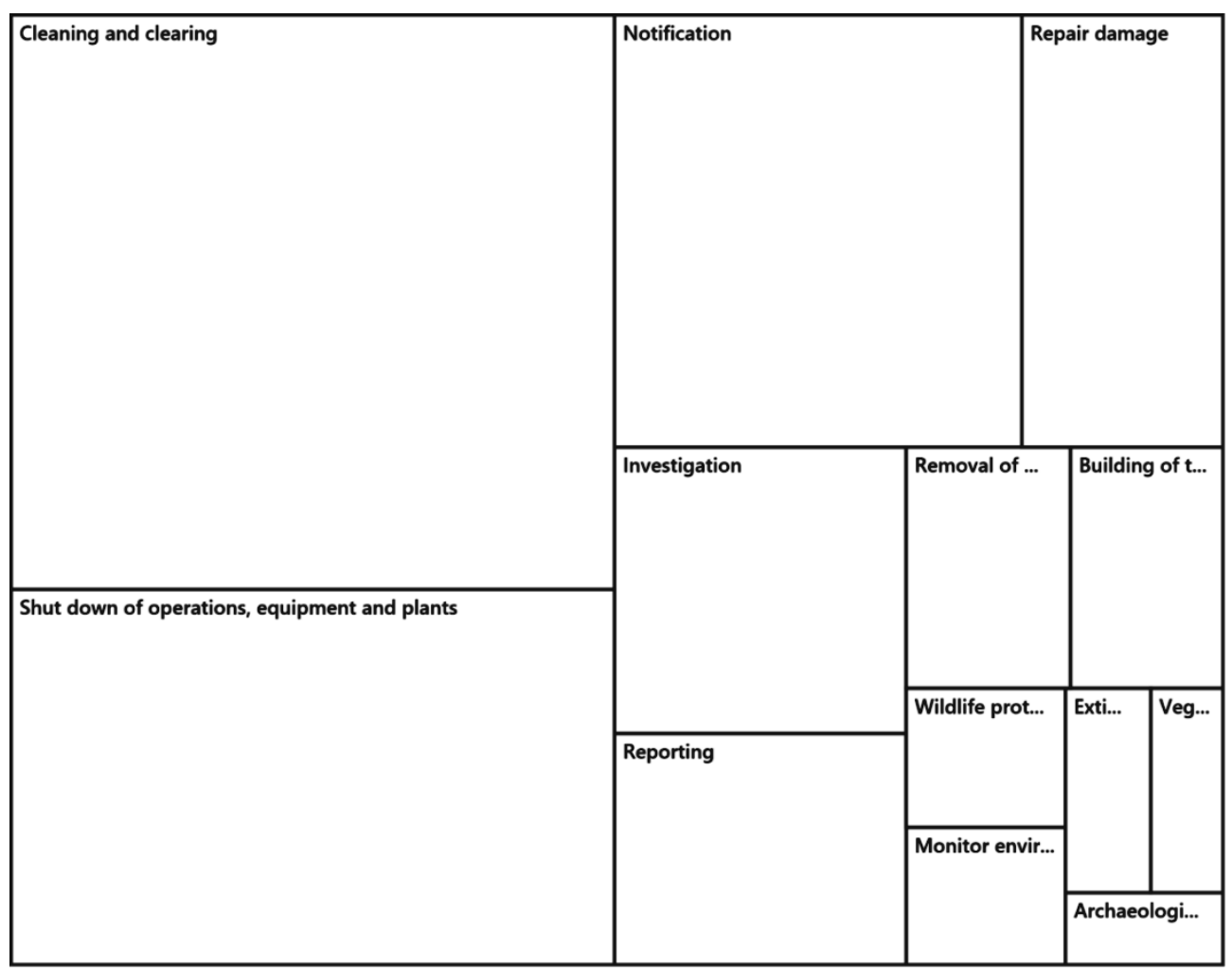

Figure 7. Tree map analysis of immediate actions- compared by number of coding references (nodes)

vegetation protection and removal (2\%), archaeological protection and removal (2\%), and extinguish the fire (2\%).

\subsection{The environmental impact of incidents}

The environmental impacts of incidents with the corresponding distribution are summarized in Table 4. Around $50 \%$ of incidents resulted in contamination of land and groundwater due to the fact that the majority of incidents are the breakdown of equipment, oil spillage, fuel spillage

Table 4. Environmental impact of incidents

\begin{tabular}{|l|c|}
\hline \multicolumn{1}{|c|}{ Environmental impact } & $\begin{array}{c}\text { Descriptive } \\
\text { statistics }\end{array}$ \\
\hline Contamination of land and groundwater & $50 \%$ \\
\hline Surface and groundwater & $11 \%$ \\
\hline $\begin{array}{l}\text { Flora and fauna including weeds and } \\
\text { pathogens }\end{array}$ & $11 \%$ \\
\hline Air quality & $5 \%$ \\
\hline Indigenous and non-indigenous heritage & $5 \%$ \\
\hline Waste & $4 \%$ \\
\hline Noise, vibration and light and visual & $4 \%$ \\
\hline Erosion and sediment control & $3 \%$ \\
\hline Breach of environmental approval/permit & $2 \%$ \\
\hline Dirt and mud on public roads & $2 \%$ \\
\hline Resources & $2 \%$ \\
\hline Acid sulphate soils & $1 \%$ \\
\hline
\end{tabular}

and other spillages. This environmental impacts denotes that incidents caused land and groundwater pollution. Similarly, surface and groundwater environmental impact means that incidents caused soil and water pollution or reduction of soil and water quality. Flora and fauna including weeds and pathogens environmental impact means that incident caused damage to vegetation and endanger wildlife which can be resulted in death of animals. Air quality environmental impact indicates that this incident caused air pollution or other reduction of air quality. Incidents related to indigenous and non-indigenous heritage signifies the cultural heritages findings during excavation process or damage of cultural findings due to construction process. Waste environmental impact indicates generated waste on the site during the construction process which was not disposed. Noise, vibration and light and visual indicate noise pollution to the environment, light effects and other. Incidents resulted in erosion and sediment control environmental impact designates that soil erosion occurred during the excavation process. The incidents with the least impact are the breach of environmental approval/ license/permit (2\%), dirt and mud on public roads $(2 \%)$, resources $(2 \%)$ and acid sulphate soils (1\%).

\subsection{Time of the environmental incidents}

During the week days, regular working time on construction sites in Australia is between 7:00 am to 6:00 pm. On Saturday, working time is between 08:00 am and 01:00 pm and Sunday is non-working day. The interval of times when environmental incidents occurred on construction 
sites is depicted in Table 5. According to data, the peak of incidents is between 10:00 am and 12:00 am, followed by incidents during period between 12:00 am and 02:00 pm. During this time period, it is a lunch break. Hence, workers are in hurry to finish the task and go for lunch, which unfortunately leads to incidents. Above $50 \%$ of environmental incidents on construction sites in Australia have occurred between 10:00 am and 04:00 pm.

\subsection{The relationship between the causes of environmental incidents and immediate actions}

The relationships between the causes of environmental incidents and immediate actions are obtained by the descriptive statistics. The results are provided in Table 6 , in which the first column presents the causes of incidents and the first row is the immediate actions. For the particular causes of incident, the relationship with the particular immediate actions is given as percentage as shown in Table 6 .
Table 5. Time of environmental incidents

\begin{tabular}{|c|c|}
\hline Time of occurrence & Descriptive statistics \\
\hline $00: 00-02: 00$ & $5 \%$ \\
\hline $02: 00-04: 00$ & $2 \%$ \\
\hline $04: 00-06: 00$ & $1 \%$ \\
\hline $06: 00-08: 00$ & $8 \%$ \\
\hline $08: 00-10: 00$ & $15 \%$ \\
\hline $10: 00-12: 00$ & $19 \%$ \\
\hline $12: 00-14: 00$ & $18 \%$ \\
\hline $14: 00-16: 00$ & $17 \%$ \\
\hline $16: 00-18: 00$ & $8 \%$ \\
\hline $18: 00-20: 00$ & $2 \%$ \\
\hline $20: 00-22: 00$ & $2 \%$ \\
\hline $22: 00-24: 00$ & $2 \%$ \\
\hline
\end{tabular}

Table 6 . The relationship between the causes of incidents and immediate actions

\begin{tabular}{|c|c|c|c|c|c|c|c|c|c|c|c|c|c|}
\hline & 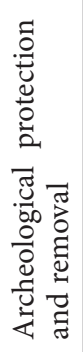 & 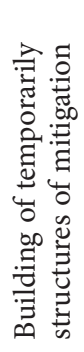 & 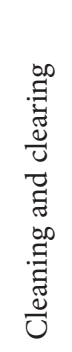 & 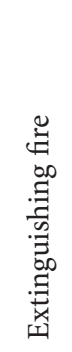 & 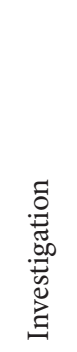 & 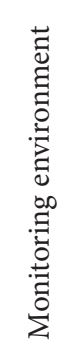 & 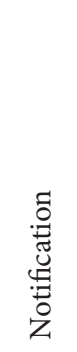 & 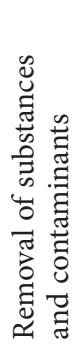 & 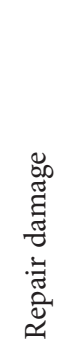 & 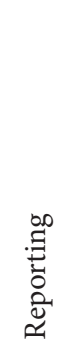 & 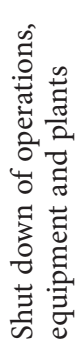 & 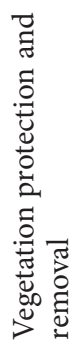 & 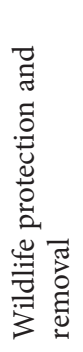 \\
\hline Equipment and plant failure & l & $1 \%$ & $41 \%$ & $3 \%$ & l & l & $14 \%$ & $3 \%$ & $12 \%$ & $4 \%$ & $23 \%$ & l & l \\
\hline Vehicular accident & I & $12 \%$ & l & l & l & l & $25 \%$ & l & l & $13 \%$ & $25 \%$ & l & $25 \%$ \\
\hline Maintenance failures & I & $13 \%$ & $25 \%$ & I & I & l & l & l & $25 \%$ & I & $25 \%$ & $12 \%$ & l \\
\hline Process failures & I & $8 \%$ & $27 \%$ & I & $8 \%$ & I & $13 \%$ & $2 \%$ & $10 \%$ & $10 \%$ & $22 \%$ & I & I \\
\hline Working hours & I & l & / & l & l & l & $62 \%$ & l & I & $13 \%$ & $25 \%$ & l & I \\
\hline $\begin{array}{l}\text { Poor waste disposal and } \\
\text { management }\end{array}$ & I & $4 \%$ & $29 \%$ & l & $11 \%$ & $4 \%$ & $18 \%$ & $7 \%$ & 1 & $11 \%$ & $18 \%$ & I & 1 \\
\hline $\begin{array}{l}\text { Archaeological and heritage } \\
\text { incident }\end{array}$ & $27 \%$ & l & I & I & $20 \%$ & $3 \%$ & $20 \%$ & l & I & $3 \%$ & $27 \%$ & l & I \\
\hline Fuel spillage & 1 & I & $52 \%$ & l & $3 \%$ & $2 \%$ & $18 \%$ & l & $7 \%$ & $3 \%$ & $13 \%$ & I & $2 \%$ \\
\hline Oil spillage & I & $1 \%$ & $48 \%$ & I & $5 \%$ & $1 \%$ & $9 \%$ & $3 \%$ & $7 \%$ & $4 \%$ & $21 \%$ & I & I \\
\hline Water spillage & I & $10 \%$ & $10 \%$ & l & / & $10 \%$ & $20 \%$ & $10 \%$ & $20 \%$ & $10 \%$ & $10 \%$ & $10 \%$ & I \\
\hline Effluent spillage & I & $3 \%$ & $30 \%$ & I & $7 \%$ & l & $20 \%$ & $13 \%$ & $3 \%$ & $7 \%$ & $17 \%$ & l & I \\
\hline Chemical spillage & I & l & $40 \%$ & I & I & $7 \%$ & $7 \%$ & $7 \%$ & $13 \%$ & $13 \%$ & $13 \%$ & l & I \\
\hline Construction material spillage & I & l & $52 \%$ & l & l & $11 \%$ & $4 \%$ & $15 \%$ & l & $11 \%$ & $7 \%$ & l & I \\
\hline Fire - flammable substances & 1 & I & l & $50 \%$ & I & l & $13 \%$ & l & $12 \%$ & I & $25 \%$ & 1 & I \\
\hline Human error and poor judgement & I & $8 \%$ & $15 \%$ & l & $10 \%$ & I & $15 \%$ & $3 \%$ & $3 \%$ & $5 \%$ & $28 \%$ & $15 \%$ & I \\
\hline $\begin{array}{l}\text { Operative failure to adhere } \\
\text { procedures }\end{array}$ & l & $3 \%$ & $11 \%$ & l & $11 \%$ & $11 \%$ & $26 \%$ & $3 \%$ & $5 \%$ & $5 \%$ & $21 \%$ & $5 \%$ & / \\
\hline Trespassing by public & / & l & / & $7 \%$ & $21 \%$ & $7 \%$ & $36 \%$ & l & l & $14 \%$ & $14 \%$ & 1 & / \\
\hline Poor weather & l & $11 \%$ & $4 \%$ & l & $19 \%$ & $4 \%$ & $21 \%$ & $13 \%$ & $6 \%$ & $6 \%$ & $15 \%$ & $2 \%$ & l \\
\hline Flooding & I & $10 \%$ & $10 \%$ & / & $10 \%$ & $10 \%$ & $10 \%$ & $10 \%$ & $10 \%$ & $10 \%$ & $20 \%$ & l & / \\
\hline Fire - weather & 1 & 1 & 1 & $78 \%$ & 1 & 1 & $11 \%$ & 1 & 1 & $11 \%$ & 1 & 1 & 1 \\
\hline Intrusion by wildlife & 1 & 1 & 1 & 1 & $11 \%$ & 1 & $22 \%$ & 1 & 1 & $6 \%$ & 1 & 1 & $61 \%$ \\
\hline
\end{tabular}


For example, the most common taken immediate actions after the breakdown of equipment and plants were cleaning and clearing (41\%), shut down of operations, equipment and plants (23\%), and notification (14\%). Regarding vehicular accident, the immediate actions were the shutdown of operations, equipment and plants (25\%), notification (25\%) and wildlife protection and removal (25\%). Further, the frequent immediate actions of maintenance failure incidents were cleaning and clearing (25\%), repair damage (25\%) and shut down of operations, equipment, and plants (25\%). Similarly, the process failures triggered cleaning and clearing (27\%), shut down of operations, equipment, and plants (22\%) and notification (17\%) as immediate actions. Further, working hour incidents generated notification (62\%) and shut down of operations and equipment and plants (25\%) as usual immediate actions. When poor waste disposal and management occurs, actions of cleaning and clearing $(29 \%)$ with actions of notification (18\%), shut down of the process, equipment and plant (18\%), investigation (11\%) and reporting (11\%) are commenced in the most of cases. While archeological and heritage incidents trigger archeological protection and removal actions (27\%), reporting (27\%), investigation (20\%) and notification $(20 \%)$ as common immediate actions after this incidents. Further, the regularly taken immediate actions after fuel spillages are: cleaning and clearing (52\%), notifications (18\%) and shut down of operation, equipment and plants (13\%). Correspondingly, the usual immediate actions in case of oil spillages are: cleaning and clearing (48\%), shut down of operations, equipment, and plants (21\%) and notifications (7\%). Water spillage triggers various immediate actions which includes: notification (20\%), repair damage (20\%), building of temporary structures for mitigation (10\%), cleaning and clearing (10\%), monitor environment (10\%), removal of materials, substances and contaminants (10\%), reporting (10\%), vegetation protection and removal (10\%) and shutdown of operation, equipment and plants (10\%). Similarly to the previous spillages, the majority of taken immediate actions in the case of effluent spillage is cleaning and clearing (30\%), notification (20\%) and shut down of operation, equipment and plants (17\%). Further, the taken immediate actions after chemical spillages on sites are cleaning and clearing $(40 \%)$, repair damage $(13 \%)$, shut down of operations, equipment and plants (13\%), reporting (13\%), and notifications (7\%). Considering spillages related to construction materials, the following immediate actions are taken: cleaning and clearing (52\%), removal of materials, substances, and contaminants (15\%), reporting (11\%) and monitor environment (11\%). Following the fire caused by flammable substance, the triggered immediate actions are extinguishing the fire (50\%), shut down of operations, equipment, and plants (25\%), notification (13\%), and repair damage (12\%). The most common taken immediate actions in case of human errors and poor judgment are: shut down of operation, equipment, and plants (28\%), vegetation protection and removal (15\%), cleaning and clearing (15\%) and notification (15\%). In the majority of cases, immediate actions after operative failure to adhere to procedures are: notification (26\%), shut down of operation, equipment, and plants $(21 \%)$, cleaning and clearing (11\%), investigation (11\%) and monitor environment (11\%). Furthermore, results show that immediate actions taken after trespassing by public incidents are notification (36\%), investigation (21\%), shut down of operations, equipment and plants (14\%), and reporting (14\%). Overall, 9 different immediate actions are taken in the case of poor weather incident and it includes notification (21\%), investigation (19\%), shut down of operations, equipment and plants (15\%), removal of materials, substances and contaminants (13\%), and building of temporary structures for mitigation (11\%). Similarly to poor weather, flooding has triggered the same immediate actions with different distribution values, shutdown of operations, equipment and plants (20\%), building of temporary structures for mitigation $(10 \%)$, cleaning and clearing (10\%), investigation (10\%), monitor environment (10\%), notification (10\%), removal of materials, substances and contaminants (10\%), repair damage (10\%), and reporting (10\%). Immediate actions in case of fire due to weather circumstances are extinguishing the fire $(78 \%)$, notification $(11 \%)$ and report $(11 \%)$. Intrusion by wildlife triggers the following immediate actions: wildlife removal and protection (61\%), notification (22\%) and investigation (11\%).

From the obtained results, it can be concluded that notification appeared as the immediate action for all incidents excluding maintenance failure and shutdown of operation, equipment and plants except for intrusion by wildlife and fire caused by weather (bushfire). On the other hand, cleaning and clearing is ranked on the first places among immediate action according to the percentage in total since it is the most taken immediate action in case of equipment and plant failure, oil and fuel spillages which are ranked as the first three incidents according to their frequency of occurrence.

\subsection{The relationship between the causes and environmental impacts}

Similarly to the relationships between the causes of incidents and immediate actions, the relationships between the causes of incidents and environmental impact are assessed based on the descriptive statistics. Hence, the relationship between the causes and the environmental impact is given as a percentage which represents the ratio of the number of cases resulted in a particular environmental impact and the total number of particular causes. The obtained results are provided in Table 7. According to the results, the equipment and plant failures are most likely to have an impact on the contamination of land and groundwater (79\%). The other environmental impacts of this incident are: surface and groundwater (7\%), flora and fauna (3\%), and others. On the other hand, the vehicular accidents resulted in an impact on flora and fauna with $100 \%$. The majority of maintenance failures have influenced flora and fauna (50\%), following surface 
Table 7. The relationship between the causes of incidents and environment impact

\begin{tabular}{|c|c|c|c|c|c|c|c|c|c|c|c|c|}
\hline & 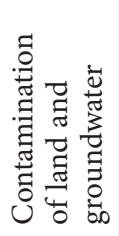 & 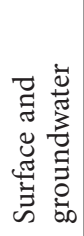 & 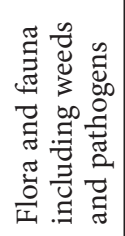 & 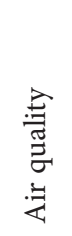 & 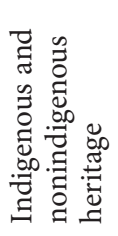 & 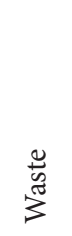 & 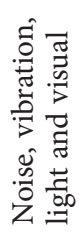 & 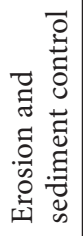 & 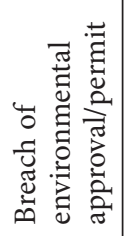 & 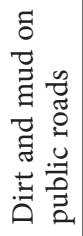 & $\begin{array}{l}\mathscr{U} \\
\breve{\Xi} \\
0 \\
\mathscr{̋} \\
\widetilde{\Xi}\end{array}$ & 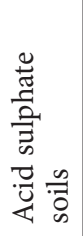 \\
\hline Equipment and plant failure & $79 \%$ & $7 \%$ & $3 \%$ & $1 \%$ & $1 \%$ & $2 \%$ & 1 & $1 \%$ & $2 \%$ & $2 \%$ & $2 \%$ & 1 \\
\hline Vehicular accident & 1 & I & $100 \%$ & / & l & / & I & / & l & I & l & I \\
\hline Maintenance failures & $17 \%$ & $33 \%$ & $50 \%$ & 1 & 1 & 1 & 1 & 1 & 1 & 1 & 1 & 1 \\
\hline Process failures & $40 \%$ & $14 \%$ & $3 \%$ & $17 \%$ & l & $3 \%$ & $9 \%$ & l & $3 \%$ & $6 \%$ & I & $6 \%$ \\
\hline Working hours & I & I & 1 & I & l & & $100 \%$ & 1 & l & l & 1 & I \\
\hline $\begin{array}{l}\text { Poor waste disposal and } \\
\text { management }\end{array}$ & $25 \%$ & $10 \%$ & $5 \%$ & / & l & $35 \%$ & l & $10 \%$ & l & $5 \%$ & $5 \%$ & $5 \%$ \\
\hline $\begin{array}{l}\text { Archaeological and heritage } \\
\text { incident }\end{array}$ & I & l & l & / & $100 \%$ & l & l & l & l & l & l & l \\
\hline Fuel spillage & $88 \%$ & $5 \%$ & $3 \%$ & 1 & 1 & 1 & 1 & 1 & 1 & 1 & $5 \%$ & 1 \\
\hline Oil spillage & $83 \%$ & $8 \%$ & 1 & I & l & $6 \%$ & I & I & $2 \%$ & I & $2 \%$ & l \\
\hline Water spillage & $14 \%$ & $29 \%$ & I & l & l & I & I & $43 \%$ & l & I & $14 \%$ & I \\
\hline Effluent spillage & $76 \%$ & 1 & 1 & 1 & 1 & $24 \%$ & 1 & 1 & 1 & 1 & 1 & 1 \\
\hline Chemical spillage & $80 \%$ & $10 \%$ & 1 & 1 & l & l & I & I & I & I & I & $10 \%$ \\
\hline Construction material spillage & $89 \%$ & 1 & 1 & I & 1 & 1 & I & 1 & 1 & $11 \%$ & 1 & I \\
\hline Fire - flammable substances & $16 \%$ & $17 \%$ & $50 \%$ & $17 \%$ & I & I & I & I & l & I & I & I \\
\hline $\begin{array}{l}\text { Human error and poor } \\
\text { judgement }\end{array}$ & $36 \%$ & $14 \%$ & $32 \%$ & $4 \%$ & l & l & / & $11 \%$ & l & $4 \%$ & l & l \\
\hline $\begin{array}{l}\text { Operative failure to adhere } \\
\text { procedures }\end{array}$ & $10 \%$ & $21 \%$ & $21 \%$ & $3 \%$ & $7 \%$ & l & l & $3 \%$ & $24 \%$ & l & $3 \%$ & $7 \%$ \\
\hline Trespassing by public & I & 1 & 1 & $18 \%$ & 1 & 1 & $82 \%$ & 1 & l & 1 & 1 & 1 \\
\hline Poor weather & $10 \%$ & $33 \%$ & $5 \%$ & $23 \%$ & $3 \%$ & $8 \%$ & 1 & $18 \%$ & 1 & $3 \%$ & 1 & 1 \\
\hline Flooding & 1 & $50 \%$ & 1 & I & 1 & $16 \%$ & 1 & $17 \%$ & 1 & 1 & $17 \%$ & 1 \\
\hline Fire - weather & 1 & 1 & $57 \%$ & $43 \%$ & 1 & 1 & 1 & 1 & 1 & 1 & 1 & 1 \\
\hline Intrusion by wildlife & I & I & $100 \%$ & I & I & I & I & I & l & I & I & I \\
\hline
\end{tabular}

and groundwater (33\%) and contamination (17\%) on the second and the third place, respectively. The environmental impacts of majority process failure incidents are contamination on land and groundwater $(40 \%)$, air quality (17\%), surface and groundwater (14\%), noise, vibration, and visual light $(9 \%)$, dirt and mud on road $(6 \%)$, acid sulphate soil $(6 \%)$, and other. Working hours incidents have resulted in noise, vibration and visual light impact (100\%). Further, poor waste disposal and management incidents have caused the majority environmental impact on waste $(35 \%)$, contamination on land and groundwater (25\%), erosion and sediment control (10\%), surface and groundwater (10\%) and other. Overall, 100\% of archaeological and heritage incidents have impacted indigenous and non-indigenous heritage. The majority of fuel spillage incidents have resulted in the contamination of land and groundwater $(88 \%)$, surface and groundwater $(5 \%)$ and resources (5\%). Similarly, oil spillages were likely to cause the contamination of land and ground water (83\%), surface and groundwater (8\%), and other. Further, the water spillages have resulted in the environmental impact on erosion and sediment control (43\%), surface and groundwater $(29 \%)$, resources $(14 \%)$, and contamination of land and groundwater (14\%). Considering other spillages, the environmental impacts of effluent spillage were contamination of land and groundwater (76\%) and waste (24\%), while the environmental impact of chemical spillages are contamination of land and groundwater (80\%), surface and groundwater (10\%) and acid sulphate soils (10\%) and construction material spillages were likely to resulted in contamination of land and groundwater (89\%) and dirt and mud on public roads (11\%). In case of fire caused by flammable substances, it has impacted flora and fauna (50\%), air quality (17\%), surface and groundwater $(17 \%)$ and contamination of land and groundwater (16\%). Human error and poor judgment incidents caused contamination of land and groundwater (35\%), impacted flora and fauna (32\%), surface and groundwater (14\%) 
and erosion and sediment control (11\%). The majority of operative failures to adhere to procedure incidents have an environmental impact on breach of environmental approval/license/permit (24\%), flora and fauna (21\%), surface and groundwater $(21 \%)$, and contamination of land and groundwater (10\%). Trespassing by public incidents has triggered noise, vibration and visual light impact (82\%) and air quality (18\%). Poor weather can cause multiple environmental influences including impact on surface and groundwater $(33 \%)$, air quality $(23 \%)$, erosion and sediment control (18\%), contamination of land and groundwater (10\%) and other. Moreover, the environmental impact of flooding was on surface and groundwater (50\%), erosion and sediment control (17\%), resources $(17 \%)$, and waste $(16 \%)$. For fire incidents caused by weather, the environmental impact was on flora and fauna (57\%) and air quality $(43 \%)$. All intrusion by wildlife incidents has impacted on flora and fauna (100\%).

\section{Discussions}

In Australia, there are a significant number of laws and regulations related to spills in order to control the waste and pollution of soil, air, and water. Some of the general regulations for environment protection in Australia are following: Western Australian Environment Protection Act (Government of Western Australia, 1986), Environmental Protection and Biodiversity Conservation Act (Australian Government, 1999), Work Health and Safety Act (Australian Government, 2011), Environmental Protection Regulations (Government of Western Australia, 2013) and others. Since this study focuses on the environmental incidents in the construction industry, the strategies to reduce or prevent some of the most frequent and the most expensive environmental incidents are proposed in this study.

This analysis has shown that among top four frequent incidents on construction sites are: equipment and plant failure, oil spillage, fuel spillage, and poor weather. A number of the proposed strategies to reduce the most frequent incident, equipment and plant failure are: 1) regular control and check-up of working equipment at the beginning of working day or before starting with construction process; 2) visual inspections; 3) regular maintenance of equipment and plants; and 4) replacement of old equipment or any parts on a regular basis. The second major incident is oil spillages. In order to reduce the occurrence of oil spillages on construction sites, some of the strategies are following: 1) regular training for employees to handle operations with oil; 2) avoid overfilling tanks or reservoirs; and 3) limitations of working hours. Similarly, fuel spillages are reduced and prevented with previous strategies. Also, construction sites should be equipped with oil and fuel kits and other spill preparation devices. Poor weather is a less controllable incident. Either hot or cold weather or rain, it could be the cause of environmental incidents on construction sites. Strategies to avoid incidents due to poor weather are following: 1) construction of temporary roofs on construction sites to reduce the impact of weather; 2) isolation of building material or chemicals from outdoor influence; 3) securing machinery and equipment in the case of extreme weather; and 4) bracing of construction components (walls, panels and others) during windy or other severe weather.

On the other hand, the most expensive incidents are flooding, poor weather, and process failures. Similarly to poor weather, flooding is an uncontrollable incident which could occur due to excessive rainfalls. Further, flood water can cause great damage to material storage on construction sites and equipment. Some of the mitigation measures to reduce damage due to flooding or prevent flooding on construction sites are: 1) enable drainage system on construction site; 2) use sandbags to prevent flood water entering into construction or material storages; 3) apply waterproof plasters for cuts; and 4) avoid construction materials, chemicals or other equipment coming into contact with flood water by removing it from place exposed to flood water on construction site. Strategies for poor weather have been mentioned in the previous chapter. Process failures are the third most expensive incidents. To reduce process failures on construction sites, the following strategies can be applied: 1) the staff on the construction site should be experienced and attend regular training related to construction process; 2) used of more efficient and advanced technology and equipment in the construction process; and 3) limited working hours. The identified environmental impacts in this study were contamination of land and groundwater, surface and groundwater, flora and fauna including weeds and pathogens, air quality, indigenous and non-indigenous heritage, waste, noise, vibration and light and visual, erosion and sediment control, breach of environment approval/permit, dirt and mud on public roads, resources, and acid sulphate soils. This result is similar to findings by Chen et al. (2005), in which environmental impacts of construction activities were soil and ground contamination, surface and underground water contamination, construction and demolition waste, noise and vibration, dust, impacts on wild and natural features, hazardous emissions and archaeological features. The differences in identified impacts were that air quality, erosion and sediment control, breach of environment approval/ permit, dirt and mud on public roads, resources, and acid sulphate soils are additional impacts in this study. On the other hand, dust and hazardous emissions are additional impacts in construction industry in the study by Chen et al. (2005). Since the majority of incidents have occurred between 10:00 am and 04:00 pm, the strategy to reduce the frequency of incidents is to make more breaks during this time period for lunch break and coffee breaks. Also, this trends and findings are similar to the time when mostly occupational accidents occurred on construction sites in Singapore (Ling, Liu, \& Woo, 2009). In addition, mostly of incidents on construction sites in Hong Kong happened around noon (Rowlinson, 1997). 


\section{Conclusions}

This study confirms that construction sites are prone to environmental incidents with a multiplicity of causes. Root Cause Analysis is performed through qualitative techniques notably thematic analysis with the aid of NVivo12 software package. The key causes of incidents and immediate actions taken after these incidents were examined from reports on the construction sites in Australia. Results have shown that the most frequent incidents that occur on construction sites were as a result of the breakdown of equipment and plant (24\%), as well as, oil spillages $(10 \%)$, fuel spillages $(8 \%)$, and poor weather $(8 \%)$. Out of the incidents occurring on construction sites, the following were found to be the most expensive in terms of estimated cost of damage and remediation: flooding, poor weather, and process failure related incident. This information is significant for project managers, site managers, and environmental managers in order to develop and prepare plans and measures to prevent or reduce incident occurrence on construction sites. Furthermore, it was found that the majority of environmental incidents that occur within construction are likely to result in the contamination of land and groundwater (50\%), surface and groundwater (11\%) and impact on flora and fauna (11\%). This study has highlighted areas that require focus in terms of the development of environmental management plans and policy guidance for the construction industry. While many researchers have the focus of construction impact of occupational health and safety as well as waste generation, this study highlights other areas that require attention in the bid to minimize the effects of construction activities on the environment. Since the focus of this study is on construction sites across Australia, results and lessons learned mainly pertain to the context of the study but however have wide-reaching implications on construction practice in other regions. In general, it demonstrates how systematic RCA can aid in effective environmental performance assessment, monitoring and management in the construction context by providing a generic framework for classification of incident causes, immediate actions and impact for the construction industry.

\section{Acknowledgements}

This research was supported by National Natural Science Foundation of China (project ID 71272088) and China Postdoctoral Science Foundation (grant number: 2017M622743).

\section{Funding}

This work was supported by the $<$ National Natural Science Foundation of China $>$ under Grant [number 71272088]; and <China Postdoctoral Science Foundation $>$ under Grant [number 2017M622743].

\section{Author contributions}

Jelena M. Andrić, Jiayuan Wang, and Ruoyu Zhong have conceived the study and were responsible for the design and structure of the paper. Jelena M. Andrić performed the environmental incident analysis using Nvivo 12 and obtained results. Jelena M. Andrić and Abdul-Majeed Mahamadu wrote drafts of the article. Jiayuan Wang and Ruoyu Zhong are supervisors.

\section{Disclosure statement}

Nothing to declare.

\section{References}

Adu, P. (2015). When to utilize manual coding or software-aided coding such as NVivo. Retrieved from

https://www.slideshare.net/kontorphilip/qualitative-dataanalysis-when-to-utilize-manual-coding-or-softwareaidedcoding-such-as-nvivo-56347603

Australian Government, Department of Environment and Energy. (1999). Environmental Protection and Biodiversity Conservation Act. Retrieved from

https://www.environment.gov.au/epbc/about

Australian Government. (2011). Work Health and Safety Act. Retrieved from https://www.legislation.gov.au/Details/ C2017C00305

Cao, G., Yang, L., Liu, L., Ma, Z., Wang, J., \& Bi, J. (2018). Environmental incidents in China: Lessons from 2006 to 2015. Science of the Total Environment, 633, 1165-1172. https://doi.org/10.1016/j.scitotenv.2018.03.271

Carroll, J. S. (1998). Organizational learning activities in highhazard industries: The logics underlying self-analysis. Journal of Management Studies, 35(6), 699-717. https://doi.org/10.1111/1467-6486.00116

Chen, Z., Li, H., \& Wong, C. T. (2005). EnvironalPlanning: Analytic network process model for environmentally conscious construction planning. Journal of Construction Engineering and Management, 131(1), 92-101. https://doi.org/10.1061/(ASCE)0733-9364(2005)131:1(92)

Chen, Z., Li, H., \& Wong, C. T. (2000). Environmental management of urban construction projects in China. Journal of Construction Engineering and Management, 126(4), 320-324. https://doi.org/10.1061/(ASCE)0733-9364(2000)126:4(320)

Dione, S., Ruwanpura, J. Y., \& Hettiaratchi, J. P. (2005). Assessing and managing the potential environmental risks of construction projects. Practice Periodical on Structural Design and Construction, 10(4), 260-266. https://doi.org/10.1061/(ASCE)1084-0680(2005)10:4(260)

Fraser, G. S., Ellis, J., \& Hussain, L. (2008). An international comparison of governmental disclosure of hydrocarbon spills from offshore oil and gas installations. Marine Pollution Bulletin, 56(1), 9-13. https://doi.org/10.1016/j.marpolbul.2007.09.032

Fuertes, A., Casals, M., Gangolells, M., Forcada, N., Macarulla, M., \& Roca, X. (2013). An environmental impact causal model for improving the environmental performance of construction processes. Journal of Cleaner Production, 52, 425-437. https://doi.org/10.1016/j.jclepro.2013.02.005 
Gangolells, M., Casals, M., Gasso, S., Forcada, N., Roca, X., \& Fuertes, A. (2009). A methodology for predicting the severity of environmental impacts related to the construction process of residential buildings. Building and Environment, 44(3), 558-571. https://doi.org/10.1016/j.buildenv.2008.05.001

Government of Western Australia, Department of Justice. (1986). Western Australian Environment Protection Act. Retrieved from https://www.legislation.wa.gov.au/legislation/statutes. nsf/main_mrtitle_304_homepage.html

Government of Western Australia. (2013). Environmental Protection (NEPM-UPM) Regulations. Retrieved from http://www.parliament.wa.gov.au/publications/tabledpapers. nsf/displaypaper/3910991a0606504314d4c15f48257c050026e 9fb/\$file/991.pdf

Guerin, T. (2014). Understanding causes of leaking plant and equipment on construction sites that can lead to soil and groundwater contamination. Remediation Journal, 25(1), 115131. https://doi.org/10.1002/rem.21418

Guerin, T. F. (2002). Heavy equipment maintenance wastes and environmental management in the mining industry. Journal of Environmental Management, 66(2), 185-199. https://doi.org/10.1006/jema.2002.0583

Guerin, T. F. (2015). Understanding the causes of spills from the supply and handling of chemicals at resource construction sites: A case study. Remediation Journal, 25(3), 115-145. https://doi.org/10.1002/rem.21436

Kim, Y. A., Ryoo, B. Y., Kim, Y. S., \& Huh, W. C. (2012). Major accident factors for effective safety management of highway construction projects. Journal of Construction Engineering and Management, 139(6), 628-640. https://doi.org/10.1061/(ASCE)CO.1943-7862.0000640

Lehtola, M. M., van der Molen, H. F., Lappalainen, J., Hoonakker, P. L., Hsiao, H., Haslam, R. A., Hale, A. R., \& Verbeek, J. H. (2008). The effectiveness of interventions for preventing injuries in the construction industry: a systematic review. American Journal of Preventive Medicine, 35(1), 77-85. https://doi.org/10.1016/j.amepre.2008.03.030

Ling, F. Y. Y., Liu, M., \& Woo, Y. C. (2009). Construction fatalities in Singapore. International Journal of Project Management, 27, 717-726. https://doi.org/10.1016/j.ijproman.2008.11.002

Lu, J., Sun, N., Xia, J., \& Hou, G. (2012). Analysis on present status and development trend of China's environment risks. Environmental Science and Management, 37(1), 10-16.

Ortiz, O., Castells, F., \& Sonnemann, G. (2009). Sustainability in the construction industry: A review of recent developments based on LCA. Construction and Building Materials, 23(1), 28-39. https://doi.org/10.1016/j.conbuildmat.2007.11.012

Perdicoúlis, A., \& Piper, J. (2008). Network and system diagrams revisited: Satisfying CEA requirements for causality analysis. Environmental Impact Assessment Review, 28(7), 455-468. https://doi.org/10.1016/j.eiar.2007.08.004

Queensland Government, Department of Transport and Main Roads (2017). Environmental incidents. Retrieved from https://www.tmr.qld.gov.au/Community-and-environment/ Environmental-management/Environmental-incidents

Rooney, J. J., \& Heuvel, L. N. V. (2004). Root cause analysis for beginners. Quality Progress, 37(7), 45-56.

Rowlinson, S. M. (1997). Hong Kong construction-site safety management. Sweet \& Maxwell.

Saldaña, J. (2013). The coding manual for qualitative researchers. Sage.

Sharrard, A. L., Matthews, H. S., \& Roth, M. (2007). Environmental implications of construction site energy use and electricity generation. Journal of Construction Engineering and Management, 133(11), 846-854. https://doi.org/10.1061/(ASCE)0733-9364(2007)133:11(846)

Shen, L. Y., \& Tam, V. W. (2002). Implementation of environmental management in the Hong Kong construction industry. International Journal of Project Management, 20(7), 535-543. https://doi.org/10.1016/S0263-7863(01)00054-0

Shin, I. J. (2013). Major industrial accidents in Korea: The characteristics and implication of statistics 1996-2011. Process Safety Progress, 32(1), 90-95. https://doi.org/10.1002/prs.11551

Taylor, D. W. (2007). The role of consequence modeling in LNG facility siting. Journal of Hazardous Materials, 142(3), 776785. https://doi.org/10.1016/j.jhazmat.2005.07.070

Wiens, J. A., \& Parker, K. R. (1995). Analyzing the effects of accidental environmental impacts: approaches and assumptions. Ecological Applications, 5(4), 1069-1083. https://doi.org/10.2307/2269355

Yang, J., Li, F., Zhou, J., Zhang, L., Huang, L., \& Bi, J. (2010). A survey on hazardous materials accidents during road transport in China from 2000 to 2008. Journal of Hazardous Materials, 184(1-3), 647-653. https://doi.org/10.1016/j.jhazmat.2010.08.085

Zolfagharian, S., Nourbakhsh, M., Irizarry, J., Ressang, A., \& Gheisari, M. (2012). Environmental impacts assessment on construction sites. In Construction Research Congress 2012: Construction Challenges in a Flat World (pp. 1750-1759). https://doi.org/10.1061/9780784412329.176 